DOI: $10.4274 /$ tod. 96729

\title{
Osteoporozlu Hastalarda D Vitamini Düzeyleri
}

\section{Vitamin D Levels in Patients with Osteoporosis}

\section{Ozet}

Amaç: Bu çalışma ile hastanemiz osteoporoz izlem polikliniğine başvuran hastaların D vitamini düzeylerini saptamayı ve ilişkili parametreleri belirlemeyi amaçladık.

Gereç ve Yöntem: İbn-i Sina Hastanesi osteoporoz izlem polikliniğinde 2003-2011 yılları arasında takipli 940 hastanın dosyaları üzerinden retrospektif olarak yaş, cinsiyet, meslek, eğitim düzeyi, menapoz durumu ve yaşı ile başvuru anındaki D vitamini düzeyleri kaydedildi. D vitamini düzeyleri 4 gruba ayrıldı: 30-80 mcg/L, yeterli (sufficient); $21-30 \mathrm{mcg} / \mathrm{L}$, yetersiz (insufficient); $11-20 \mathrm{mcg} / \mathrm{L}$, eksik (deficient); 0-10 mcg/L, osteomalazik (osteomalasic) kabul edildi. D vitamini düzeyi, her bir parametreyle istatistiksel olarak karşılaştırıldı.

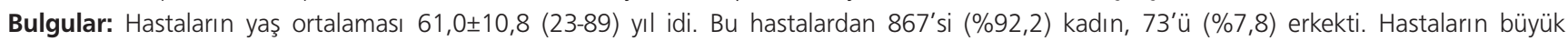
çoğunluğu ev hanımıydı $(\% 72,6)$. Hastaların eğitim düzeyi genelde ilkokuldu $(\% 45,6)$. Hastalardan menopoza girenlerin sayısı 777 (\%82,7) ve ortalama menapoz yaşı 45,69 $\pm 6,16$ 'ydı. Hastaların D vitamini düzeyleri ortalaması $26,13 \pm 18,62 \mathrm{mcg} / \mathrm{L}$ idi. D vitamini düzeyine göre grupladığımızda yaklaşık \%70'inin normalin altında kaldığı görüldü. Osteomalazik düzeyde değerleri olan hasta \%16,3'tü. D vitamini düzeyi yeterli olan hasta \%31,5'ti. D vitamini düzeyiyle cinsiyet arasında anlamlı fark bulundu ve kadınlarda D vitamini daha düşük saptandı $\left(\chi^{2}=9,63\right.$, p=0,022). D vitamini düzeyinin meslek, eğitim düzeyi, yaş ve menopoz süresi ile bir ilişkisi bulunamadı.

Sonuç: Osteoporoz izlem polikliniğimize başvuran hastalarda D vitamini düzeyleri \%70'e yakın oranda normalin altında bulundu. Ayrıca kadınlarda D vitamini düzeyi anlamlı biçimde daha düşük saptandı. Bu konuda risk faktörlerine odaklı ileri çalışmalara ihtiyaç vardır. (Türk Osteoporoz Dergisi 2011;17:68-70)

Anahtar kelimeler: D vitamini, osteoporoz, cinsiyet

\section{Summary}

Aim: In this study, we aimed to determine vitamin D levels and related parameters of patients referring to our osteoporosis follow-up clinic. Material and Methods: Age, gender, occupation, education level, menopausal state, menopause age and vitamin D levels on admission were recorded retrospectively from files of 940 patients, who had been followed between years 2003-2011 at ibn-i Sina osteoporosis follow-up clinic. Vitamin D levels divided into four groups and accepted as 30-80 mcg/L sufficient, $21-30 \mathrm{mcg} / \mathrm{L}$ insufficient, $11-20 \mathrm{mcg} / \mathrm{L} \mathrm{deficient} \mathrm{and} \mathrm{0-10} \mathrm{mcg/L}$ osteomalasic.

Results: Mean age of the 940 patients was $61.0 \pm 10.8$ (23-89) years. 867 (92.2\%) were female and $73(7.8 \%)$ were male patients. Most of the patients were housewomen (72.6\%). Educational level of the patients was usually primary school (45.6\%). The number of menopausal patients was $777(82.7 \%)$ and mean menopause age was $45.69 \pm 6.16$. The mean vitamin D level of the patients was $26.13 \pm 18.62 \mathrm{mcg} / \mathrm{L}$. When we grouped patients according to vitamin D levels, approximately $70 \%$ were below normal. Patients who had osteomalasic levels were $16.3 \%$. Patients with sufficient vitamin D levels were $31.5 \%$. There was significant difference between sex and vitamin D levels and it was lower in women $\left(\chi^{2}=9.63, p=0.022\right)$. No relation was found between occupation, educational level, age, menopause time and vitamin $D$ levels.

Conclusion: Approximately $70 \%$ of the patients admitted to our osteoporosis follow-up clinic had vitamin D levels lower than normal. In addition, it has been found that vitamin D levels were significantly lower in women. There is advanced need for studies focusing on risk factors. (Turkish Journal of Osteoporosis 2011;17:68-70)

Key words: Vitamin D, osteoporosis, gender

Yazıșma Adresi/Address for Correspondence: Dr. Memet Kurt, Ankara Üniversitesi Tıp Fakültesi, Fiziksel Tıp ve Rehabilitasyon Anabilim Dalı, Ankara, Türkiye Tel.: +90 3125082497 Gsm: +90 5557053021 E-posta: mkdrcurt@gmail.com Geliș Tarihi/Received: 03.01.2012 Kabul Tarihi/Accepted: 04.01.2012 Türk Osteoporoz Dergisi, Galenos Yayınevi tarafindan basılmıştır. / Turkish Journal of Osteoporosis, published by Galenos Publishing. 


\section{Giriş}

Son yıllarda D vitamininin potansiyel yararlarına ilgi giderek artmaktadır. Bu durum, osteoporotik kırık çalışmaları, D vitamini ve kalsiyum meta-analizlerinden elde edilen sonuçların yorumlanması ile ortaya konulmuştur.

Serum D vitamini düzeyleri kalsiyum, fosfor, fibroblast growth factor-23, parathormon vb. ile düzenlenir ve homeostatik dengede tutulur. $D$ vitamini düşüklüğünün, osteomalazi ve osteoporoz (OP) gibi metabolik kemik hastalıklarının yanı sıra kanser, diyabet, multipl skleroz ve kardiyovasküler olaylar ile ilişkisi tespit edilmiştir (1-4). D vitamininin, kalsiyum metabolizması yanında güçlü immün modulatuvar etkileri de vardır (5). Genel olarak <30 mcg/L hipovitaminoz, $50 \mathrm{mcg} / \mathrm{L}$ optimal kabul edilmekle birlikte, optimal 25(OH)D serum düzeyleri konusunda farklı ülkelerden farklı görüşler bildirilmektedir. 25(OH)D serum düzeyleri < 5-7 ng/ml osteomalaziye, $<10-12 \mathrm{ng} / \mathrm{ml}$ sekonder hiperparatiroidi ve OP'ye yatkınlık yapar ve $>18-20 \mathrm{ng} / \mathrm{ml}$ normal veya yeterli kabul edilir (6). Ancak optimal serum 25(OH)D düzeylerine dair uluslararası bir konsensus yoktur (2).

Biz bu çalışmada hastanemiz OP izlem polikliniğinde OP tanısıyla takip edilen hastaların $D$ vitamini düzeylerini saptamak ve $D$ vitamini düzeyini etkileyebilecek bazı parametreleri belirlemek istedik.

\section{Gereç ve Yöntem}

Bu çalışmaya İbn-i Sina Hastanesi Osteoporoz İzlem Polikliniğinde 2003-2011 yılları arasında takip olan 940 hasta (867 kadın, 73 erkek) alındı. Hastaların dosyaları üzerinden retrospektif olarak yaş, cinsiyet, meslek, eğitim düzeyi, menopoz durumu, menopoz yaşı ve başvuru anındaki $D$ vitamini düzeyleri kaydedildi. D vitamini düzeylerine göre hastalar 4 farklı gruba ayrıldı: 30-80 $\mathrm{mcg} / \mathrm{L}$; yeterli (sufficient), 21-30 mcg/L; yetersiz (insufficient), $11-20 \mathrm{mcg} / \mathrm{L}$; eksik (deficient) ve $0-10 \mathrm{mcg} / \mathrm{L}$; osteomalazik kabul edildi (7). illişkili olabilecek parametreler D vitamini düzeyiyle karşılaştırıldı.

İstatistiksel analizler için SPSS (Statistical Package for Social Sciences) 16.0 programı ile Student T test, One-Way Anova, Ki kare ve Pearson korelasyon analizleri kullanılmış ve $p<0.05$ anlamlı olarak kabul edilmiştir. Ortalamalar, ortalama \pm standard sapma cinsinden verilmiştir.

\section{Bulgular}

Hastaların demografik özellikleri Tablo 1'de verilmiştir. Ortalama

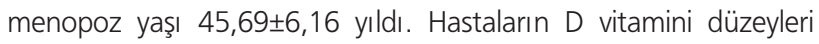
ortalaması $26,13 \pm 18,62 \mathrm{mcg} / \mathrm{L}$ idi. Kadınların ortalama D vitamini düzeyleri $(25,71 \pm 18,50 \mathrm{mcg} / \mathrm{L})$, erkeklerin ortalamasından $(31,05 \pm$ $19 ., 36 \mathrm{mcg} / \mathrm{L})$ daha düşük saptandı $(p=0.01)$.

D vitamini düzeyi ve cinsiyete göre hastaları gruplandırdığımızda (Tablo 2), $644(\% 68,5)$ hastanın D vitamini düzeyi normalin altında kaldı. Bunlardan osteomalazik düzeyde (<10 mcg/L) değerleri olan hasta sayısı 153 (\%16,3); bunun 145'i $(\% 16,7)$ kadın, 8'i $(\% 11,0)$ erkek hasta idi. D vitamini düzeyi $>30$ mcg/L olan hasta sayısı 296 $(\% 31,5)$ idi. Erkekler ile kadınlar arasında 4 grupta da anlamlı fark saptandı $\left(\chi^{2}=9,63, \quad p=0,022\right)$. Bu farkın hangi gruptan kaynaklandığının tespiti için alt gruplar karşılaştırıldığında, erkeklerde $(\% 46,6)$ kadınlardan $(\% 30,2)$ daha fazla yeterli D vitamini düzeyi saptandı $\left(\chi^{2}=8,35, p=0,004\right)$.

Kadınların menopoz durumuna göre $D$ vitamini düzeylerini karşılaştırdığımızda; $90(\% 9,6)$ premenopozal hastanın (yaş ortalaması $45,12 \pm 7,38$ yıl) D vitamini düzeyi $24,82 \pm 17,91 \mathrm{mcg} / \mathrm{L}$ ve $777(\% 82,7)$ postmenopozal hastanın (yaş ortalaması 63,03 $\pm 9,33$ yıl) $25,81 \pm 18,58$ mcg/L olarak saptand. Menopoz durumuna göre $D$ vitamini düzeyleri arasında fark bulunmadı ( $p>0.05$ ).

D vitamini düzeyi ile hasta yaşı, mesleği ve eğitim düzeyi arasında ilişki bulunamadı ( $p=0,408 ; p=0,147 ; p=0,105$, sırasıyla). Ayrıca kadınlarda yaş ve menopoz süresi ile $\mathrm{D}$ vitamini düzeyleri arasında bir ilişki bulunamadı $(r=0,03 p>0,05 ; r=0,03 p>0,05$, sırasıyla).

\section{Tartışma}

Bu çalışmada kadınların D vitamini düzeyleri erkeklerden anlamlı olarak düşük saptandı. Yaklaşık olarak erkeklerin yarısında ve kadınların üçte birinde $D$ vitamini normal düzeylerde tespit edildi. D vitamini düzeyi ile hasta yaşı, mesleği ve eğitim düzeyi arasında ilişki bulunamadı. Kadınlarda menopoz durumu ile D vitamini düzeyi arasında ilişki saptanmadı.

Tablo 1. Hastaların Demografik Özellikleri $(n=940)$

\begin{tabular}{|l|c|}
\hline Değişkenler & \\
\hline Yaş (yıl), ortalama \pm SD & $61,0 \pm 10,8(23-89)$ \\
\hline Cinsiyet, $\mathrm{n}(\%)$ & $73(7,8)$ \\
Erkek & $867(92,2)$ \\
Kadın & \\
\hline Eğitim, n (\%) & $235(25,0)$ \\
Okuma yazma bilmiyor & $429(45,6)$ \\
Illkokul & $63(6,7)$ \\
Ortaokul & $101(10,7)$ \\
Lise & $112(11,9)$ \\
Üniversite & \\
\hline Meslek, n (\%) & $682(72,6)$ \\
Ev hanımı & $33(3,5)$ \\
İşçi & $95(10,1)$ \\
Memur & $130(13,8)$ \\
Emekli & \\
\hline
\end{tabular}

Tablo 2. Cinsiyete Göre D Vitamini Düzeylerinin Karșllaștırması

\begin{tabular}{|l|c|c|c|}
\hline D vitamini (mcg/L) & Kadın $\mathbf{n}(\%)$ & Erkek $\mathbf{n}(\%)$ & Total $\mathbf{n}(\%)$ \\
\hline$>30$ (sufficient) $^{*}$ & $262(30,2)$ & $34(46,6)$ & $296(31,5)$ \\
\hline $21-30$ (insufficient) & $212(24,5)$ & $11(15,1)$ & $223(23,7)$ \\
$11-20$ (deficient) & $248(28,6)$ & $20(27,4)$ & $268(28,5)$ \\
0-10 (osteomalasic) & $145(16,7)$ & $8(11,0)$ & $153(16,3)$ \\
\hline
\end{tabular}

* D vitamini düzeyinin $30 \mathrm{mcg} / \mathrm{L}$ üstü veya altı olması durumuna göre kadın ve erkekler arasında anlamlı fark bulundu $(X 2=9.63, p=0.022)$. 
Dünyanın değişik ülkelerinden yapılan bildiriler, D hipovitaminozun dünya çapında bir problem olduğunu göstermektedir ve bu durum majör bir sağlık sorunu olarak karşımıza çıkmaktadır (8-10). Yetersiz 25(OH)D düzeyleri oldukça yaygındır ve frajilite kırıklarında, özellikle de kalça kırığında, dolayısıyla mortalitede etkilidir $(11,12)$.

Yetersiz D vitamini düzeyleri ileri yaş, kadın cinsiyet, yüksek enlemler, kış mevsimi, koyu cilt rengi, sınırlı güneş ışığı maruziyeti, diyetle alım eksikliği, malabsorbsiyon sendromları, kapalı ortam ve giyim tarzı ile ilişkilendirilmiştir (2,13-15). Güneş ışığının yetersiz olduğu ekvatordan uzak bölgelerde deri yoluyla üretilen $D$ vitamini düzeylerinde azalma gözlenmiştir. Avrupa toplumu bu açıdan risk altındadır (16). Yine, kapalı giyimde belirginleşen $D$ vitamini düşüklüğü durumunda, oral alım veya zenginleştirilmiş gıdalarla D vitamini takviyesi önerilmektedir $(17,18)$. Bununla birlikte, haftada en az 2 kez, yüz ve ellerin 10-15 dk, direk güneş ışığına maruziyeti ile yeterli D vitamini sentezi olmaktadır (8). Ayrıca, modern giyim tarzında da $D$ vitamini düşüklüğüne rastlayabilmekteyiz. Bu durum, olasılıkla ultraviyole ışığı filtreleyen güneş koruyucu krem kullanımı ile ilişkili olabilir $(2,7)$.

Hekimsoy ve arkadaşlarının 2010 yılında (kırsalda yaşayan 20 yaş üzeri 391 erişkinde ve kış mevsiminde) yaptığı bir çalışmada ortalama 25(OH)D düzeyi 16,9 $13,09 \mathrm{ng} / \mathrm{mL}$ bulunmuştur. Bunların \%13,8'i yetersiz (20-29,99 ng/mL), \%74.9'u eksik (<20 $\mathrm{ng} / \mathrm{mL}$ ) ve $\% 11,3^{\prime}$ ü yeterli (30 ve $>30 \mathrm{ng} / \mathrm{mL}$ ) bulunmuş ve 25(OH)D eksikliğinin kadınlarda $(\% 78,7)$ erkeklerden $(\% 66,4)$ daha yaygın olduğu tespit edilmiştir (19). Bizim çalışmamızda ise, ortalama D vitamini düzeyi daha yüksek $(26,1 \pm 18,6 \mathrm{mcg} / \mathrm{L})$ bulundu. Bunların \%23,7'si yetersiz (21-30 mcg/L), \%28,5'i eksik (11-20 mcg/L), \%16.3'ü osteomalazik (<10 mcg/L) ve \%31,5'u yeterli saptandı. 25(OH)D eksikliği benzer biçimde kadınlarda $(\% 69,8)$ erkeklerden $(\% 53,4)$ daha yaygın olarak tespit edildi. Ortalama ve yüzde farkları; kırsal yaşam, mevsim, yaş ve çalışma populasyonunun farklıı̆ı̆ıla izah edilebilir.

Ülkemizden Başaran ve arkadaşlarının 2006 yılında 286 hastada osteoporozda vitamin D düzeyinin yaşam kalitesi üzerine etkisine dair yaptığı bir çalışmada; vitamin D düzeyi ile yaş, vücut kitle indeksi, eşlik eden hastalık sayısı, menopoz süresi, risk faktörleri, ağrı düzeyi ve diyetle kalsiyum alımı arasında korelasyon bulunamamıştır (20). Bizim çalışmamızda da D vitamini düzeyiyle yaş, meslek, eğitim düzeyi ve menopoz durumu arasında bir ilişki saptanamadı. Eğitim düzeyiyle $D$ vitamini düzeyleri karşılaştııldığında ortaya çıkan göreceli artış anlamlı bulunamadı. D vitamini düşüklüğü, kronik ağrılı hastalarda tek başına karşımıza çıkabilmektedir (4). Fizik tedavi polikliniğimize, yaygın ağrı şikayetiyle başvuran hastaların birçoğunda D vitamini eksikliği saptanmaktadır. Holick ve arkadaşlarının klinik pratik için hazırladıkları kılavuzda, sadece risk grubu hastalarda D vitamini düzeyine bakılması önerilmiştir. Bu endikasyonda; rikets, osteomalazi, osteoporoz, kronik böbrek yetmezliği, karaciğer yetmezliği, Crohn hastalığı, hiperparatirodi, ilaç (glukokortikoid, antiepileptik, antifungal vs.) kullanımı, hamile ve emziren kadınlar, düşme ve nontravmatik kırık öyküsü olan yaşı hastalar, obez çocuklar, vücut kitle indeksi $>30 \mathrm{~kg} / \mathrm{m}^{2}$ olan bireyler, sarkoidoz ve bazı lenfoma hastaları yer almaktadır (21). Bu açıdan yaygın ağrıda ve risk grubunda bulunan hastalarda D vitamini düzeyi bakılması akılcı bir davranış olacaktır.
Sonuç olarak, osteoporoz izlem polikliniğimize başvuran hastaların yaklaşık \%70'inde D vitamini düzeyleri normalin altında bulundu. Ayrıca, kadınlarda D vitamini düzeyi anlamlı biçimde erkeklerden daha düşük saptandı. Çalışmamızda hasta sayısı yeterli olmasına rağmen, ilişkili olabilecek faktörlerin sınırlı tutulması bu düşüklüğü açıklamak için yetersiz kalmıştır. Bu konuda daha etraflı, risk faktörlerine odaklı yeni çalışmalara ihtiyaç vardır.

\section{Kaynaklar}

1. Gallagher JC, Sai AJ. Vitamin D insufficiency, deficiency, and bone health. J Clin Endocrinol Metab 2010;95:2630-3.

2. Pérez-López FR, Brincat $M$, Erel $C T$, Tremollieres F, Gambacciani $M$, Lambrinoudaki I, et al. EMAS position statement: Vitamin D and postmenopausal health. Maturitas. 2011 Nov 17. [Epub ahead of print]

3. Zhang R, Naughton DP. Vitamin D in health and disease: current perspectives. Nutr J 2010;9:65

4. Cannell JJ, Hollis BW, Zasloff M, Heaney RP. Diagnosis and treatment of vitamin D deficiency. Expert Opin. Pharmacother 2008;9:107-18.

5. de Paula FJ, Rosen CJ. Vitamin D safety and requirements. Arch Biochem Biophys 2011 (In Press).

6. Gómez Alonso C, Naves Díaz M, Rodríguez García M, Fernández Martín JL, Cannata Andía JB. [Review of the concept of vitamin D "sufficiency and insufficiency"]. Nefrologia 2003;23:73-7.

7. Holick MF. Vitamin D deficiency. N Engl J Med 2007:357:266-81.

8. Iqbal $R$, Khan AH. Possible causes of vitamin D deficiency (VDD) in Pakistani population residing in Pakistan. J Pak Med Assoc 2010;60:1-2.

9. Miljkovic I, Bodnar LM, Cauley JA, Bunker CH, Patrick AL, Wheeler VW, et al. Low prevalence of vitamin $D$ deficiency in elderly AfroCaribbean men. Ethn Dis 2011;21:79-84.

10. Mithal A, Wahl DA, Bonjour JP, Burckhardt P, Dawson-Hughes B, Eisman JA, et al. IOF Committee of Scientific Advisors (CSA) Nutrition Working Group. Global vitamin D status and determinants of hypovitaminosis D. Osteoporos Int 2009;20:1807-20.

11. Dixon T, Mitchell P, Beringer T, Gallacher S, Moniz C, Patel S, et al. An overview of the prevalence of 25-hydroxy-vitamin D inadequacy amongst elderly patients with or without fragility fracture in the United Kingdom. Curr Med Res Opin 2006;22:405-15.

12. Kuroda T, Shiraki M, Tanaka S, Ohta H. Contributions of 25hydroxyvitamin $\mathrm{D}$, co-morbidities and bone mass to mortality in Japanese postmenopausal women. Bone 2009;44:168-72.

13. Gaugris S, Heaney RP, Boonen S, Kurth $H$, Bentkover JD, Sen SS. Vitamin $D$ inadequacy among post-menopausal women: a systematic review. QJM 2005:98:667-76.

14. Erkal MZ, Wilde J, Bilgin Y, Akinci A, Demir E, Bödeker RH, et al. High prevalence of vitamin D deficiency, secondary hyperparathyroidism and generalized bone pain in Turkish immigrants in Germany: identification of risk factors. Osteoporos Int 2006;17:1133-40.

15. Guzel R, Kozanoglu E, Guler-Uysal F, Soyupak S, Sarpel T. Vitamin D Status and Bone Mineral Density of Veiled and Unveiled Turkish Women. J Womens Health Gend Based Med 2001;10:765-70.

16. Scharla SH. Prevalence of subclinical vitamin D deficiency in different European countries. Osteoporos Int 1998;8:S7-12.

17. Glerup H, Mikkelsen K, Poulsen L, Hass E, Overbeck S, Thomsen J, et al. Commonly recommended daily intake of vitamin $D$ is not sufficient if sunlight exposure is limited. J Intern Med 2000;247:260-8.

18. McKenna MJ. Differences in vitamin D status between countries in young adults and the elderly. Am J Med 1992;93:69-77.

19. Hekimsoy Z, Dinç G, Kafesçiler S, Onur E, Güvenç Y, Pala T, et al. Vitamin $D$ status among adults in the Aegean region of Turkey. BMC Public Health 2010;10:782.

20. Başaran S, Güzel R, Benlidayı IC, Uysal FG. Osteoporozda Vitamin D Düzeyinin Yaşam Kalitesi Üzerine Etkisi. Osteoporoz Dünyasından 2006;12:35-8.

21. Holick MF, Binkley NC, Bischoff-Ferrari HA, Gordon CM, Hanley DA, Heaney RP, et al. Evaluation, treatment, and prevention of vitamin D deficiency: an Endocrine Society clinical practice guideline. J Clin Endocrinol Metab 2011;96:1911-30. 